\title{
CONCEPÇÕES DE MEIO AMBIENTE E EDUCAÇÃO AMBIENTAL POR ALUNOS DO ENSINO FUNDAMENTAL EM CRUZ DAS ALMAS (BA): UM ESTUDO DE CASO
}

Leopoldo Melo Barreto ${ }^{1}$ Jamiri Soares Cunha ${ }^{2}$

Resumo: O desenvolvimento sustentável se concretiza como um dos principais desafios da humanidade, sendo a Educação Ambiental (EA) um instrumento imprescindível para a estabilização de novos métodos desse desenvolvimento. $O$ presente estudo objetivou verificar o entendimento dos conceitos básicos que permeiam a EA e perceber o entendimento geral dos alunos da série final do ensino básico, do município de Cruz das Almas-Bahia. Os resultados mostram que os educandos têm um bom entendimento sobre o tema geral da $E A$, entretanto, quando os questionamentos são mais específicos, percebeu-se que os alunos das escolas públicas municipal e estadual apresentam uma maior dificuldade de entendimento, quando comparados aos da escola particular.

Palavras-chave: Escolas; Recôncavo; Ecopedagogia.

${ }^{1}$ Universidade Federal do Recôncavo da Bahia. E-mail: leopoldo.barreto@gmail.com

2 Universidade Federal do Recôncavo da Bahia. E-mail: jamiricunha@gmail.com

Revbea, São Paulo, V. 11, № 1: 315-326, 2016.

revista brasileira educação ambiental 


\section{Introdução}

O termo Educação Ambiental (EA) tem sido usado desde 1948 (SECAD/MEC, 2007), embora as suas diretrizes tenham começado a ser traçadas apenas em 1972, na 1를 Conferência das Nações Unidas sobre o Meio Ambiente, em Estocolmo (Suécia). Nesta conferência os dirigentes políticos elaboraram a Declaração de Estocolmo, que defende a inserção da Educação Ambiental na Agenda Internacional. Segundo Borges e Tachibana (2005), uma das resoluções apresentadas neste relatório foi a indicação da necessidade de promover a educação dos cidadãos comuns no sentido de buscar as soluções para problemas ambientais, instituindo-se assim a prática da EA.

No Brasil, a Constituição promulgada em 1988 dedicou-se a fomentar um capítulo inteiro às questões ambientais, visando assegurar direitos e determinar obrigações, prioridades e competências relativas ao Meio Ambiente. Entretanto, Chiavenato (1997, apud LEITE, 2011) relata que esta ação não significou a diminuição dos problemas ambientais no Brasil, mundialmente conhecido pela devastação das florestas, pela caça e pesca predatórias, de difícil controle pelas Instituições Fiscais de Uso e Regulamentação dos Recursos Naturais Brasileiros.

Em 1992, na cidade do Rio de Janeiro, o Tratado de Educação Ambiental para as Sociedades Sustentáveis e Responsabilidade Global propõe princípios e um plano de ação para os educadores ambientais, estabelecendo uma relação entre as políticas públicas de educação ambiental e a sustentabilidade (United Nations Education, Scientific and Cultural Organization [UNESCO], 1992b). Neste tratado, enfatizam-se os processos participativos na promoção do meio ambiente, voltados para a sua recuperação, conservação e melhoria, bem como para a melhoria da qualidade de vida (Jacobi, 2003), compromisso assumido por mais de 170 países. Nesta Conferência (RIO 92), a implantação da Agenda 21 foi o mais importante compromisso firmado entre os países, onde mais de 2.500 recomendações práticas foram estabelecidas tendo como objetivo preparar o mundo para os desafios do século XXI (UNESCO, 1992a).

Já em 1995 foi criada a Câmara Técnica Temporária de Educação Ambiental no Conselho Nacional de Meio Ambiente (CONAMA), onde os princípios orientadores para 0 trabalho foram a participação, a descentralização, o reconhecimento da pluralidade e a diversidade cultural, bem como a interdisciplinaridade, esse último, um ponto necessário para 0 resgate e a construção de saberes (JACOBI, 2003).

Nesse contexto, instituiu-se o termo ecopedagogia, que segundo Gadotti (2001) visa à promoção da aprendizagem a partir da vida cotidiana, sendo uma pedagogia democrática e solidária. Esta cotidianidade já tinha sido referida por Freire (1959) em seus primeiros escritos: " $E$ nesse sentido que se pode afirmar que o homem não vive autenticamente enquanto não se acha integrado com a sua realidade" (p. 9). Essa integração com o cotidiano facilita na promoção do aprendizado. 
$\mathrm{Na}$ atualidade, segundo a Política Nacional de Educação Ambiental (PNEA), entende-se por educação ambiental os processos por meio dos quais indivíduo e a coletividade constroem valores sociais, conhecimentos, habilidades, atitudes e competência voltadas para a conservação do meio ambiente. De acordo com o Art. 20 (BRASIL, 1999): "A educação ambiental é um componente essencial e permanente da educação nacional, devendo estar presente, de forma articulada, em todos os níveis e modalidades do processo educativo, em caráter formal e não-formal'.

A atual situação do meio ambiente no mundo e em particular no Brasil, revela a importância de efetivar o papel da escola como instituição responsável pela formação integral dos cidadãos, por meio de uma educação que responda precisamente a realidade, de modo a dar uma resposta adequada a seus problemas (DIAZ, 2002).

Segundo Grun (2000), no Brasil, existe uma tendência em analisar as questões ambientais como uma unidade de ensino das disciplinas Ciências e Biologia. Isso acaba por reduzir a abordagem necessariamente multifacetada, ética e política das questões ambientais aos seus aspectos biológicos. Ainda segundo o autor, estes, por sua vez, são reduzidos à sua dimensão física e esta é, então, finalmente reduzida a uma questão técnica.

Para Leff (2001) a Educação Ambiental exige uma integração de conhecimentos e aproximações sistêmicas, holísticas e interdisciplinares que, se limitadas à reorganização do saber disponível, são insuficientes para satisfazer essa demanda de conhecimentos. A questão ambiental requer novos conhecimentos teóricos e práticos para sua compreensão e resolução.

Assim, pergunta-se se a EA está sendo introduzida na educação formal dos estudantes e, se a mesma está sendo internalizada pelos alunos. Baseado nisso, o presente estudo objetivou verificar o entendimento dos conceitos básicos que permeiam a Educação Ambiental de modo a perceber 0 entendimento geral dos alunos da série final do ensino fundamental em escolas públicas e particulares em Cruz das Almas, Bahia.

\section{Material e métodos}

O estudo foi conduzido em três escolas da rede Baiana de ensino da cidade de Cruz das Almas, cidade situada no Recôncavo Baiano entre as coordenadas geográficas Latitude $12^{\circ} 40^{\prime} 12^{\prime \prime} \mathrm{S}$ e Longitude $39^{\circ} 06^{\prime} 07^{\prime \prime}$. A cidade foi fundada em 1897, possui uma área de $145,7 \mathrm{~km}^{2}$, uma população de aproximadamente 63.299 habitantes, onde em 2012 houveram 9.385 matrículas no ensino fundamental (IBGE, 2013).

O estudo foi conduzido durante o ano de 2013, sendo os questionários aplicados nos meses de agosto, setembro e outubro.

Inicialmente, fez-se uma ampla pesquisa bibliográfica acerca do tema EA, tanto em termos internacionais quanto nacionais, a fim de fundamentar a formulação de um instrumento de recolha de dados eficiente para, a partir

revista brasileira educação ambiental 
desse, fazer uma avaliação das concepções de meio ambiente, de modo a averiguar de modo superficial o efeito da educação ambiental como tema transversal na educação básica.

Em paralelo, pesquisou-se na Secretaria de Educação do Estado e Município as escolas cadastradas na região de Cruz das Almas, sede da Universidade Federal do Recôncavo da Bahia (UFRB), sendo elencada três escolas, uma em cada âmbito: estadual, municipal e particular. O processo de escolha foi casual, baseado nos critérios de: i) possuir ensino fundamental e ii) estar nas proximidades da UFRB. Em um segundo momento foi agendado visitas para a apresentação da proposta e calendarização na aplicação dos questionários e conversas com a gestão da escola.

O universo amostral selecionado foi o último ano do ensino fundamental (9a série) de cada escola e os alunos convidados a participarem da investigação. Previamente houve uma explanação sobre o objetivo da inquirição e da importância da veracidade dos dados ali informados. O questionário foi elaborado de forma semiestruturado, com questões fechadas e abertas, de modo a possibilitar aos alunos, em algumas questões, expressarem seus pensamentos e versaram sobre a prática desenvolvida dentro da escola acerca do tema.

Após a aplicação do questionário as respostas fechadas foram tabulados no software Microsoft Excel 2011, sendo realizado com base nos resultados, uma análise porcentual das respostas, das médias e uma análise comparativa entre os âmbitos escolares. As questões abertas não foram apenas classificadas como certas ou erradas, de acordo com a interpretação do pensamento desenvolvida sobre o tema indagado, mas também levado em consideração o grau de aprofundamento do conhecimento exposto.

Em conseguinte a metodologia proposta elaborou-se uma cartilha educativa sobre o tema Meio Ambiente, que teve como base responder as dificuldades apresentadas pelos educandos durante a coleta dos dados. A cartilha foi distribuída ao final da pesquisa para os alunos da série objeto do estudo, bem como permitindo a reprodução por parte da escola para ampla distribuição nas demais turmas.

\section{Resultados e discussão}

O universo amostral pesquisado foi composto por 174 alunos da 9a série do ensino fundamental, turno matutino e/ou vespertino, sendo 61 alunos da escola municipal, 37 da particular e 76 da estadual (Figura 1). O número de alunos compõe quase em sua totalidade cada série em cada escola. 


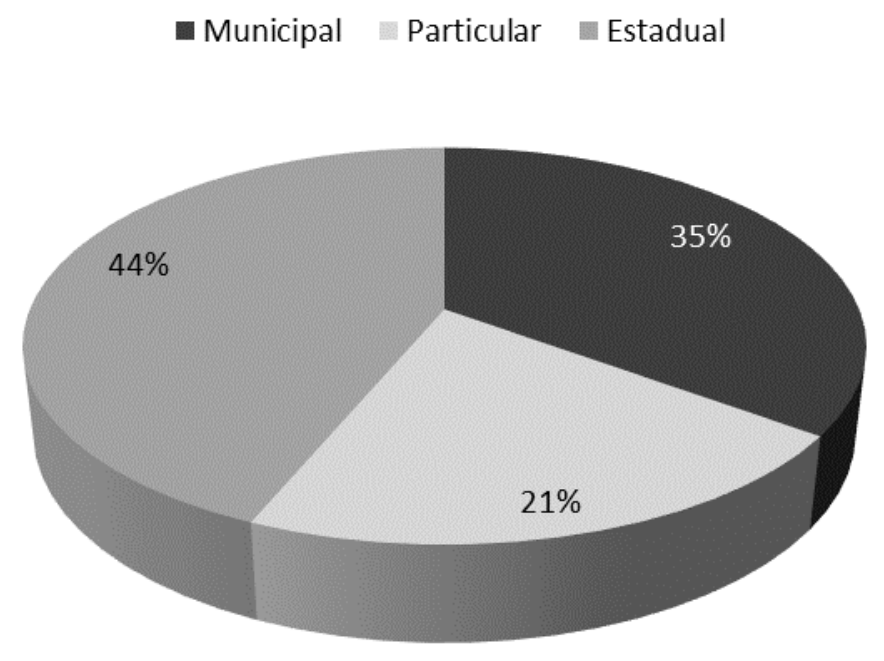

Figura 1: Participação efetiva de cada escola na investigação.

Com relação a compreensão dos alunos acerca do termo Meio Ambiente, percebeu-se que grande parte $(44,3 \%)$ restringem o conhecimento aos elementos vivos e naturais, ou seja, eles excluem os elementos culturais e a forma como as atividades humanas interferem com este elemento, não acreditando que o Meio Ambiente é composto também de vilas, cidades e todo o ambiente construído pelo homem. Dentre as escolas estudadas, o maior grau de entendimento correto sobre o Meio Ambiente foi observado na escola Particular $(67,6 \%)$, seguido da escola Municipal $(55,7 \%)$ e por fim a Estadual $(50,0 \%)$.

Ainda nesse contexto, analisando o conhecimento dos educandos sobre o lixo inorgânico, observou-se um ótimo entendimento do quesito reciclagem, tendo a maioria dos estudantes $(91,9 \%)$ compreensão de que a reciclagem é o processo que transforma materiais usados em novos produtos. Esse entendimento pensa-se ser fruto da mídia, principalmente televisiva, a qual observaremos mais adiante ter grande influência sobre os jovens. Esse fato é relevante, uma vez que o lixo transforma negativamente o meio ambiente e que o descarte inapropriado por parte das pessoas tem grande impacto.

Em relação à definição de produtos ecologicamente corretos todas as escolas apresentaram percentualmente mais respostas erradas do que corretas (Figura 2), levando-nos a uma preocupação ampliada. A análise das respostas mostrou que a maioria dos entrevistados se atém apenas ao resultado final do produto, levando em consideração se este é ou não de matéria prima renovável. A maioria dos estudantes não considerou o processo de produção e erraram a questão, visto que para que um produto seja considerado ecologicamente correto, o seu processo de fabricação deve ser de impacto mínimo ou nulo, fato esse desconhecido pelos alunos. 


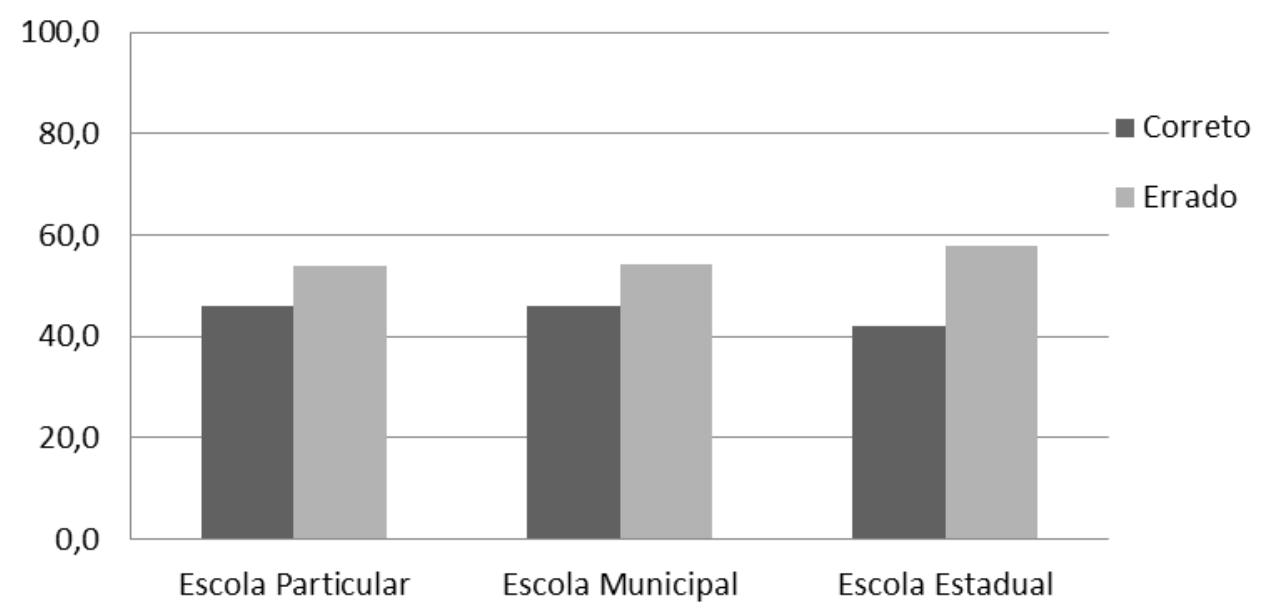

Figura 2: Respostas dos alunos para o item produtos ecologicamente corretos?

Outro desafio imposto é a interação do ser humano com o meio ambiente, que precisa ser visto de forma que não o agrida, ou seja, não prejudicar o desenvolvimento vindouro, entendido atualmente como sustentável. A maioria dos estudantes $(89,2 \%)$ entendem que o desenvolvimento sustentável é a capacidade de interagir com o meio no presente de modo a contribuir com o futuro. Entretanto, acreditamos que é preciso uma avaliação mais segura para termos resultados convincentes acerca dessa visão. Já quando aprofundamos mais o questionamento à conhecimentos específicos, como por exemplo, o lençol freático e mata ciliar, os estudantes da escola particular tiveram nítida vantagem frente aos de escolas públicas (Figura 3 e 4), o que sugere que o aprofundamento ou modelo de ensino-aprendizagem é favorecido na primeira, levando novamente a preocupações sobre o conteúdo lecionado, mesmo de forma transversal, nas escolas públicas.

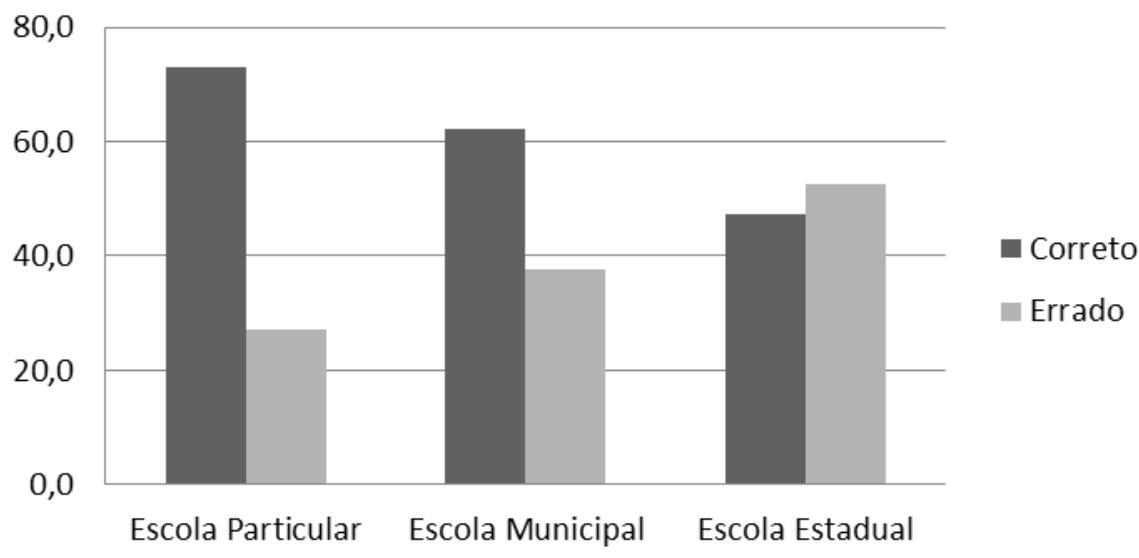

Figura 3: Respostas dos alunos quanto ao item principais contaminantes do lençol freático. 


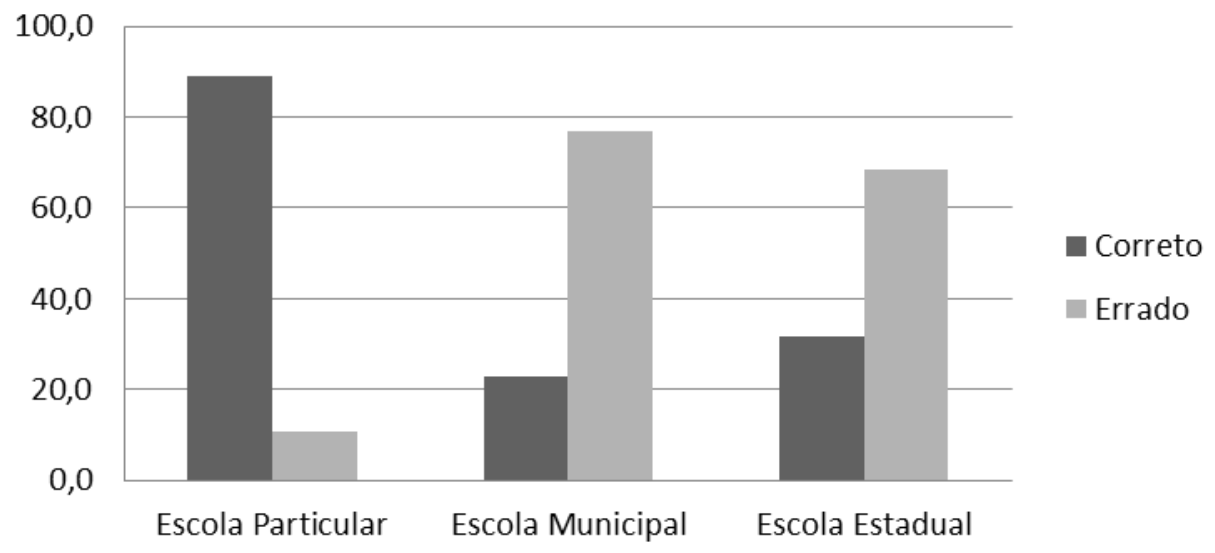

Figura 4: Respostas dos alunos quanto ao item mata ciliar.

Com relação ao conhecimento sobre os principais poluentes de corpos hídricos percebeu-se que a maioria dos estudantes (96,7\%) tem conhecimento, sendo os mais citados "produtos químicos e matéria orgânica" (97,3\%). Mesmo os alunos que citaram "limo e algas" como principais poluentes da água, maior índice na escola Estadual, podemos entender que seja por estes existem em água poluída. Talvez assim cogitando a má interpretação ao questionamento, pois sabemos que a alga e o limo são reflexos de uma poluição no meio aquático, mas não a causa.

Sobre o item degradação da Terra, que resulta no desequilíbrio do ecossistema e perda da biodiversidade, os estudantes da escola particular também apresentaram mais conhecimento. Embora de modo geral, tenha sido percebido uma percepção do que é degradável pela maioria dos estudantes (Figura 5).

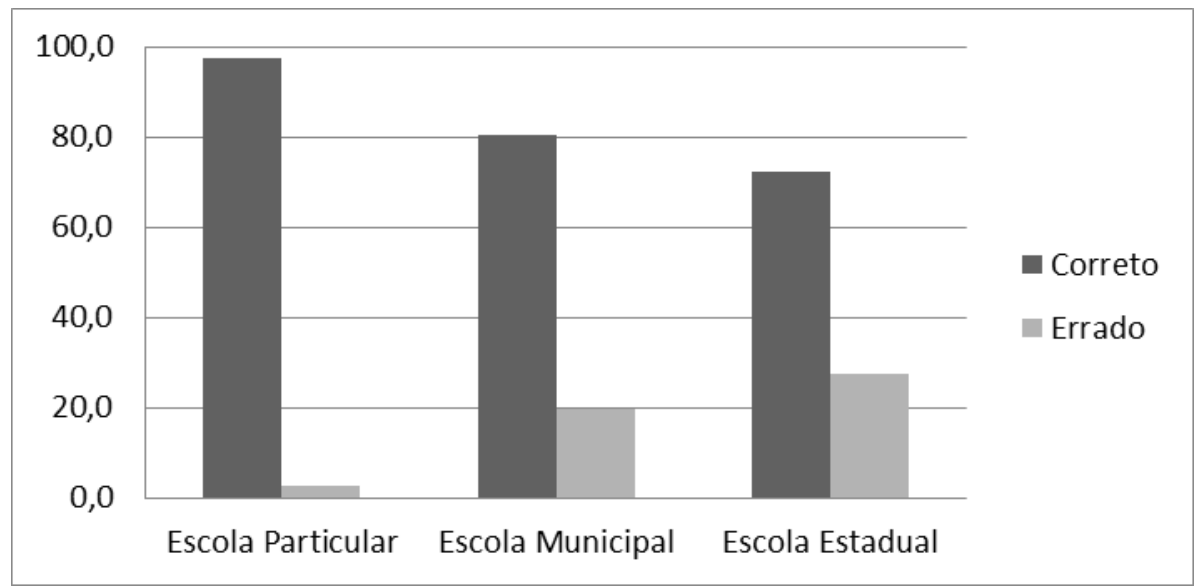

Figura 5: Respostas dos alunos quanto ao item formas de degradação da Terra.

Sabe-se que a Educação Ambiental é um processo de formação, com caráter multiplicador, que funciona a partir do momento em que se compreende 
que os atuais desafios ambientais exigem o comprometimento de um número cada vez maior de pessoas na busca de soluções. É notável a amplitude da Educação Ambiental e a necessidade em se adotar enfoques interdisciplinares que reflitam a complexidade atual. Possivelmente em algumas disciplinas a abordagem de cunho ambiental não foi bem explicitada pelos educadores, fazendo com que a escola não fosse eleita, principalmente a Municipal $(49,2 \%)$ e a Estadual (64,5\%), como a principal fonte de informações sobre o meio ambiente, onde observamos na Tabela 1 que a mídia televisiva e a internet superam a escola quando se fala de aprendizado para o Meio Ambiente. Outra questão a se observar é a diferença no costume de leitura entre a escola particular (32,4\% revistas e $24,3 \%$ jornais) quando comparada a outras escolas.

Tabela 1: Percentual sobre as fontes de informação acerca do Meio Ambiente.

\begin{tabular}{lcccccc}
\hline & Televisão & Internet & Revistas & Jornais & Escolas & Outros \\
\hline Escola Particular & 94,6 & 91,9 & 32,4 & 24,3 & 83,8 & 8,1 \\
Escola Municipal & 59,0 & 44,3 & 1,6 & 8,2 & 49,2 & 3,3 \\
Escola Estadual & 75,0 & 48,7 & 9,2 & 15,8 & 64,5 & 3,9 \\
\hline
\end{tabular}

Já na Tabela 2 (página seguinte), onde resgatamos da memória dos alunos em quais disciplinas no ensino fundamental esses aprendiam sobre EA, percebeu-se que na escola particular Geografia (78,4\%) e Química (48,6\%) foram em disparado as que mais diretamente abordavam o tema. Já na esfera Municipal percebe-se nitidamente que a disciplina Ciências $(91,8 \%)$, seguida de Geografia $(50,8 \%)$ são as mais relacionadas ao tema, o que concorda com o resultado na escola Estadual, onde também Ciências $(68,4 \%)$ e Geografia $(36,8 \%)$ foram mais citadas.

O fato da escola não ser vista pelos alunos como o principal veículo educador acerca do Meio Ambiente nos traz questionamentos, uma vez que deveria ser a escola, a principal fonte das questões ambientais, dos problemas que nos cercam e por fim habilitar os educandos a resolvê-los, principalmente através de programas ambientais práticos vinculados às disciplinas, programas esses que engravidassem de sentidos a teoria. Quando se fala de prática aliada a teoria, Mazzarino (2012, p. 59) já bem coloca:

A escola precisa trabalhar com atitudes e com a formação de valores e isso, certamente, não é aprendido pelo estudante dentro de quatro paredes. A prática, a constatação, a observação e, principalmente, a emoção levam à mudança de conceitos e à criação de novas formas de pensar e agir em relação ao meio ambiente. Dessa forma o educador ambiental na escola necessita, assim como o educando, apreciar e valorizar o trabalho que está propondo-se realizar, buscando formação, informações, publicações acerca do assunto, sentindo-se parte integrante do processo. 
Tabela 2: Percentual das respostas em relação as disciplinas onde os alunos aprendem sobre Educação Ambiental.

\begin{tabular}{lccc}
\hline \multicolumn{1}{c}{ Disciplinas } & $\begin{array}{c}\text { Escola } \\
\text { Particular }\end{array}$ & $\begin{array}{c}\text { Escola } \\
\text { Municipal }\end{array}$ & $\begin{array}{c}\text { Escola } \\
\text { Estadual }\end{array}$ \\
\hline Geografia & 78,4 & 50,8 & 36,8 \\
Ciências & 21,6 & 91,8 & 68,4 \\
Química & 48,6 & 0,0 & 1,3 \\
Física & 29,7 & 0,0 & 0,0 \\
Biologia & 8,1 & 0,0 & 1,3 \\
História & 8,1 & 0,0 & 0,0 \\
Português & 2,7 & 11,5 & 0,0 \\
Informática & 0,0 & 6,6 & 0,0 \\
Relações Humanas & $*$ & 11,5 & $*$ \\
Redação & 0,0 & 1,6 & 0,0 \\
Espanhol & 0,0 & 1,6 & 0,0 \\
Eixo temático & $*$ & $*$ & 9,2 \\
Meio Ambiente & $*$ & $*$ & 6,6 \\
Ciências e suas & $*$ & $*$ & 11,8 \\
tecnologias & & & 2,6 \\
Educação Física & 0,0 & 0,0 & 2,6 \\
Agricultura & $*$ & $*$ & 3,9 \\
Cidadania & $*$ & $*$ & 1,3 \\
Artes & 0,0 & 0,0 & 2,6 \\
TMl & $*$ & $*$ & \\
\hline$\left({ }^{\prime}\right.$ A disciplna não & & & \\
\hline
\end{tabular}

$\left(^{*}\right)$ A disciplina não é ofertada pela instituição

Os meios de comunicação televisivo foram considerados pelos alunos das escolas os maiores responsáveis pela ampla difusão de informações sobre as questões ambiental. Observou-se que na escola particular os alunos têm mais acesso à internet, notadamente ligado ao poder aquisitivo, tornando esta uma possível forma de se trabalhar com a temática, dentro e fora da escola, como por exemplo em Blog's e Vlog's. Nas escolas públicas também existe essa possibilidade uma vez que nas escolas visitadas há salas de informática com internet, no entanto os professores não fazem uso, talvez pela falta de formação. Assim a mídia pode (e deve) ser usada dentro da proposta pedagógica da escola, de forma a tornar o processo de absorção de informações mais dinâmico e motivador, só dependendo da própria gestão possibilitar tal uso, seja através de capacitação docente, seja através de melhorar a infraestrutura.

Os pesquisadores Oliveira et al. (2010), avaliando as experiências de aprendizagem da Educação Ambiental e Patrimonial dos estudantes do ensino médio de uma escola pública de Goiânia-GO, observaram que o conceito de EA parece ainda não ter sido bem assimilado na escola, reduzindo-se ao conservacionismo ou a reciclagem de materiais. Dessa forma ainda afirma que predomina o pensamento unidirecional, estando longe do ideal, porque a 
Educação Ambiental se desdobra em diversas outras situações que devem ser promovidas e fomentadas a fim de desenvolver nos estudantes e em toda a comunidade escolar o real sentido que este termo carrega consigo. Perguntamos nós: faltam projetos orientados para a ação, onde incentivam a visão crítica do aluno a ponto de os mesmos pensarem soluções viáveis?

Souza (2007), por sua vez, em trabalho realizado sobre EA em municípios do Cariri paraibano, PB junto com educadores da região, questionou sobre o desenvolvimento das atividades de Educação Ambiental no ensino fundamental de modo que $90 \%$ dos educadores entrevistados responderam que desenvolvem as suas atividades pedagógicas sobre Meio Ambiente de modo individual, enquanto os demais responderam que desenvolvem atividades de forma interdisciplinar, de forma coletiva e também de outras formas. Para a autora isto revela que há uma grande dificuldade por parte dos educadores em trabalhar as suas atividades pedagógicas de modo coletivo e interdisciplinar, envolvendo toda a escola, criando, desse modo, enormes obstáculos ao desenvolvimento da temática Educação Ambiental na escola, e contrária ao que é proposto na Lei 9.795 de 1999 (BRASIL, 1999).

Autores como Fracalanza (2004) elenca perguntas, tais como: "que proposta de educação ambiental está sendo praticada nas escolas? Que relações práticas, ditas de EA, têm com o currículo escolar e com as disciplinas do currículo praticado?" (p.6). O próprio autor já conclui afirmando que os problemas na Educação Ambiental no âmbito das escolas se referem à metodologia e às práticas de ensino utilizadas pelos professores; à formação dos professores; à organização e ao funcionamento das escolas.

Porém vale ressaltar que este processo educativo não deve ser considerado exclusivo do ambiente escolar, pois todos os cidadãos têm direito a Educação Ambiental, como também tem o dever, enquanto parte integrante do meio ambiente, de ser um educador ambiental (SILVA, 2008, p.6).

Como resultado final confeccionou-se uma cartilha educativa acerca do Meio Ambiente a qual fora distribuída nas escolas participantes, sendo bem aceita pela gestão e pelos professores, mas que coincidiu com o final do ano letivo de 2013, assim não possibilitando uma rediscussão do impacto gerado pela cartilha.

\section{Conclusões}

Concluímos com a presente investigação que o tema Meio Ambiente vem sendo trabalhado nas escolas da região de Cruz das Almas. No entanto, percebemos diferentes graus de aprofundamento entre os âmbitos particular, municipal e estadual, refletindo talvez a preparação do professor para abordar tais conteúdos ou talvez, a própria infraestrutura fornecida pela a escola. Outro fator que merece destaque, não nomeado como conclusão, mas como reflexão conclusiva, é o grau de motivação que sabe-se ser necessário no espaço escolar, desde os educadores até os educandos, sendo questão determinante no processo de ensino aprendizagem. Por fim observamos uma deficiência de Revbea, São Paulo, V. 11, № 1: 315-326, 2016. 
projetos orientados para a ação dentro das escolas, onde o aluno apenas vê a teoria da Educação Ambiental, mas bastante distanciado de práticas que gerem uma consciência critica para a resolução das questões ambientais.

\section{Agradecimentos}

Agradecemos primeiramente ao Programa Institucional de Bolsa de Extensão (PIBEX) da Universidade Federal do Recôncavo da Bahia (UFRB), e as três escolas que permitiram a investigação tanto do espaço escolar como a participação dos alunos.

\section{Referências}

BORGES, F.H.; TACHIBANA, W.K. A evolução da preocupação ambiental e seus reflexos no ambiente dos negócios: uma abordagem histórica. Anais do ENCONTRO NACIONAL DOS ESTUDANTES DE ENGENHARIA DE PRODUÇÃO, 25, Porto Alegre, 2005. Porto Alegre: PUC-RS, 2005. p.52355242.

BRASIL. Ministério da Educação e do Desporto. A implantação da educação ambiental no Brasil. 1 $\stackrel{a}{ }$ ed. Brasília-DF, 1998. 166p. Disponível em: $<$ http://www.icmbio.gov.br/educacaoambiental/images/stories/biblioteca/educac ao ambiental/A implantação da EA no Brasil.pdf>. Acesso em: 24 abr. 2014.

BRASIL. Ministério da Educação (1999). Educação ambiental. Lei oํ 9.795, de 27 de abril de 1999. Disponível em: $<$ http://portal.mec.gov.br/secad/arquivos/pdf/educacaoambiental/lei9795.pdf>. A cesso em: 12 fev. 2014.

CHIAVENATO, J.J. (). Desenvolvimento sustentável para todos. In: KUPSTAS, M. Ecologia em debate. (org.). São Paulo: Moderna, 1997.

DIAZ, A.P. Educação Ambiental como Projeto. Porto Alegre: Artmed, 2002, 168p.

FREIRE, P. Educação e atualidade brasileira. Tese de concurso. Recife: Universidade Federal do Recife. 1959139 p.

FRACALANZA, H. As pesquisas sobre educação ambiental no Brasil e as escolas: alguns comentários preliminares. Anais do Colóquio de Pesquisadores em EA, 1, Pelotas: UFPel, 2004. p.55-77.

GADOTTI, M. Pedagogia da terra: Ecopedagogia e educação sustentável. In: CLASCO (Ed.), Paulo Freire y la agenda de la educacion latinoamericana en el siglo XXI (pp. 81-132). Buenos Aires, 2001.

GRUN, M. Ética e Educação Ambiental: a conexão necessária. Campinas: Papirus, 2000. 
IBGE - Instituto Brasileiro de Geografia e Estatística. Cidades, Cruz das Almas, Bahia. $2013 . \quad$ Disponível em: $<$ http://cidades.ibge.gov.br/xtras/perfil.php?codmun=290980>. Acesso em: 24 abr. 2014.

JACOBI, P. Educação Ambiental, cidadania e sustentabilidade. Cadernos de Pesquisa, v.18, p.189-205, 2003

LEITE, M.S. A Educação Ambiental e a formação para a cidadania. Monografia (Licenciatura em Biologia). Universidade de Brasília, DF, 2011.

LEFF, E. Epistemologia ambiental. São Paulo: Cortez, 2001, 240 p.

LOUREIRO, C.F.B. Trajetória e Fundamentos da Educação Ambiental. 2. ed. São Paulo: Cortez, 2006.

MAZZARINO, J.M.; MUNHOZ, A.V.; KEIL, J.L. Currículo, Transversalidade e Sentidos em Educação Ambiental. REVBEA, Rio Grande, v.7, n.2, p.51-61. 2012.

OLIVEIRA, M.L.; CORREIA, R.S.; GENOVESE, C.L.C.R. Conhecer para preservar: o documentário como projeto de intervenção escolar. Enciclopédia Biosfera, Goiana, v.6, n.9, 2010.

SATO, M. Educação Ambiental. São Carlos: RIMA, 2004, 66 p.

SILVA, M.M.P. Uma educação para a sustentabilidade ambiental. Revista mundo jovem, Porto Alegre, ano 46, n. 385, 2008.

SECAD/MEC. Educação Ambiental: aprendizes de sustentabilidade. Secretaria de Educação Continuada, Alfabetização e Diversidades. Brasília-DF: Cadernos SECAD 1, 2007.

SOUZA, J.M.F. Educação ambiental no ensino fundamental: metodologias e dificuldades detectadas em escolas de município no interior da Paraíba. João Pessoa: Editora Universitária, 2007, 191p.

UNESCO - UNITED NATIONS EDUCATIONAL, SCIENTIFIC AND CULTURAL ORGANIZATION. Rio declaration on environment and development, 1992. Disponível em: <http://habitat.igc.org/agenda21/rio-dec.htm>. Acesso em: 23 Abr. 2014.

UNESCO - UNITED NATIONS EDUCATIONAL, SCIENTIFIC AND CULTURAL ORGANIZATION. Agenda 21, 1992. Disponível em: <http://habitat.igc.org/agenda21/index.htm>. Acesso em: 23 Abr. 2014. 